\title{
O PAPEL DA FORMULAÇÃO DE QUESTÕES DURANTE A LEITURA COMPARTILHADA DE LIVROS NA EDUCAÇÃO INFANTIL
}

\author{
Aline E. Pereira ${ }^{1,2^{*}}$ \\ Rosângela Gabriel ${ }^{1 *}$ \\ Laura M. Justice ${ }^{2 * *}$ \\ ${ }^{1}$ Universidade de Santa Cruz do Sul, Santa Cruz do Sul, RG, Brasil/ CNPq \\ ${ }^{2}$ College of Education and Human Ecology, Ohio State University, Columbus, Ohio,

Resumo

A leitura compartilhada de livros é uma das atividades que mais contribui para o desenvolvimento da linguagem das crianças pequenas (JUSTICE; SOFKA, 2010; SÉNÉCHAL, 2015; EVANS; SAINT-AUBIN, 2005; SÉNÉCHAL; LEFEVRE, 2002) e tem efeitos na aquisição do registro da linguagem escrita (BUS et al., 1995). Entretanto, os efeitos dessa contribuição dependem do modo como o adulto interage e incentiva a participação da criança na discussão e reflexão para além do texto. Crianças pequenas que participam ativamente da leitura compartilhada de livros conduzida por um adulto, o qual interage com elas por meio de perguntas, rotulagem de palavras e seus referentes, apresentam ganhos maiores em vocabulário do que as crianças que ouvem passivamente a leitura do livro (SÉNÉCHAL et al., 1995). Além disso, o uso de questões desempenha um papel fundamental no direcionamento da atenção e na manutenção da participação da criança na atividade da leitura compartilhada. O objetivo do presente estudo é (1) determinar a frequência com que os professores da educação infantil fazem perguntas durante a leitura compartilhada de livros com seus alunos; e (2) identificar os tipos de perguntas, em relação a perguntas básicas $v s$ complexas. Participaram do estudo nove professores e seus respectivos alunos, entre 2 e 5 anos, de uma cidade do interior do Rio Grande do Sul, Brasil. Duas sessões de leitura compartilhada de cada professor $(n=18)$ foram gravadas em vídeo, transcritas e codificadas por meio de uma versão adaptada do Systematic Assessment of Book Reading-Transcript Coding Version 2.1 (ZUCKER et al., 2017). Os resultados mostram que durante as dezoito sessões de leitura compartilhada, os professores elaboraram um total de 329 pergun-

\footnotetext{
* Doutoranda no Programa de Pós-Graduação em Letras da Universidade de Santa Cruz do Sul (RS, Brasil), com bolsa Capes modalidade I. Bolsista PDSE CAPES Edital 47/2017 na Ohio State University (2018-2019). Email: linep.scs@gmail.com. ORCID: https://orcid.org/0000-0002-3601-4039

** Docente Permanente do Programa de Pós-Graduação em Letras da Universidade de Santa Cruz do Sul (RS, Brasil). Bolsista Produtividade em Pesquisa do Conselho Nacional de Desenvolvimento Científico e Tecnológico - CNPq Brasil. Email: gabriel@unisc.br. ORCID: https://orcid.org/0000-0002-2535-2497

*** Doutora em Filosofia e Ciências da Linguagem e Diretora Executiva do Schoenbaum Family Center e do Crane Center for Early Childhood Research and Policy, ambos ligados ao College of Education and Human Ecology, da Ohio State University - OSU, Columbus, Ohio (USA). Email: justice.57@osu.edu ORCID: https:// orcid.org/0000-0002-0580-0280.
} 
tas, classificadas em duas categorias: questões básicas e questões complexas. Do total de questões, as básicas tiveram uma frequência maior $(n=285)$ e as questões complexas foram formuladas com menos frequência $(n=44)$. Os resultados da presente pesquisa estão alinhados com estudos (PENTIMONTI et al., 2018; BECK; MCKEOWN, 2001; GIROLAMETTO et al., 2000) que demonstram que os professores, em geral, formulam perguntas básicas com mais frequência quando comparadas às perguntas complexas. Diante disso, ressaltamos a importância de chamar a atenção dos professores sobre o valor da leitura compartilhada, mediada por uma interação que privilegie a formulação de questões, ampliando a proporção de questões complexas, tendo em vista a influência que esse tipo de atividade exerce no desenvolvimento linguístico-cognitivo das crianças.

Palavras-chave: Leitura Compartilhada; Educação Infantil; Questões Simples e Complexas; Systematic Assessment of Book Reading-Transcript Coding Version 2.1.

\section{THE ROLE OF QUESTION FORMULATION DURING THE} SHARED READING OF BOOKS IN CHILDHOOD EDUCATION

\section{Abstract}

The shared reading of books is one of the activities that most contributes to the development of young children's language (JUSTICE; SOFKA, 2010; SÉNÉCHAL, 2015; EVANS; SAINT-AUBIN, 2005; SÉNÉCHAL; LEFEVRE, 2002) and has effects in the acquisition of the written language registers (BUS et al., 1995). However, the effects of this contribution depend on how the adult interacts with and encourages the child's participation in the discussion and reflection beyond the text. Young children who actively participate in adult-led shared reading of books, which interact with them through questions, word-labeling, and referents, have greater gains in vocabulary than children who passively hear the book reading (SÉNÉCHAL et al., 1995). In addition, the use of questions plays a key role in directing attention and maintaining the child's participation in the activity of shared reading. The purpose of this study is to (1) determine how often preschool teachers ask questions during shared reading of books with their students, and (2) identify the types of questions that teachers asked related to basic vs. complex questions. A total of nine teachers and their students aged 3 to 5 years, from a city in the interior of Rio Grande do Sul, Brazil, participated in the study. Two shared reading sessions of each teacher $(n=18)$ were recorded on video, transcribed and coded using an adapted version of the Systematic Assessment of Book ReadingTranscript Coding Version 2.1 (ZUCKER et al., 2017). The results show that during the eighteen shared reading sessions, teachers compiled a total of 329 questions, classified into two categories: basic questions and complex questions. From the total, the basic ones had a higher frequency $(\mathrm{n}=285)$ and complex questions were formulated less frequently $(\mathrm{n}=44)$. The results of this research are in line with other studies (PENTIMONTI et al., 2018; BECK; MCKEOWN, 2001; GIROLAMETTO et al., 2000) that show that teachers usually ask basic questions more frequently when compared to complex questions. Therefore, we emphasize the importance of calling teachers attention to the value of shared reading, mediated by an interaction that favors the formulation of questions, seeking to expand the proportion of complex questions, given the influence that this type of activity has on the cognitive and linguistic development of children.

Keywords: Shared Reading; Childhood Education; Simples vs. Complex Questions; Systematic Assessment of Book Reading-Transcript Coding Version 2.1. 


\section{Introdução}

O Brasil exibe estatísticas alarmantes quando se considera a qualidade da leitura realizada por estudantes ao fim do ensino fundamental. No âmbito internacional, os resultados obtidos mais recentemente por estudantes brasileiros, avaliados pelo Programa Internacional de Avaliação de Estudantes (PISA, 2015), evidenciam um quadro penoso para o Brasil no que tange à proficiência em leitura. A última edição do programa, realizada em 2015, classificou o país no $59^{a} \mathrm{em}$ leitura, caindo de 493 pontos, alcançados em 2012, para 407 em 2015.

Na mesma linha, o desempenho de crianças na Avaliação Nacional de Alfabetização (ANA, 2016) evidencia que apenas 13\% das crianças nessa etapa do ensino fundamental alcançou o nível esperado de proficiência em leitura (nível 4). As demais se dividem em nível 1 (22\%), nível 2 (33\%) e nível 3 (32\%). Considerando o total de níveis e os percentuais, mais da metade das crianças (55\%) evidenciam grandes deficiências em leitura no $3^{\circ}$ ano. Crianças que estão no nível 1 apresentam dificuldades para fazer a leitura de palavras com diferentes quantidades de sílabas e estruturas silábicas, por exemplo, a partir da imagem de um mamão, a criança apresenta dificuldade para identificar a palavra 'mamão'; no nível (2), apresentam dificuldades de compreensão de textos simples e de resgate de informações contidas no texto, normalmente, presentes no título ou na frase inicial (ANA, 2016).

A constatação desses dados deve nos levar a pensar estratégias para que as próximas gerações de estudantes não reproduzam os resultados evidenciados pelos exames nacionais e internacionais. Estudiosos argumentam que ações pedagógicas amparadas na ciência da leitura e investimento em políticas públicas específicas para a primeira infância (0 -5 anos), com o desenvolvimento de medidas de intervenção no tempo certo (em oposição ao termo precoce, de fato inadequado neste contexto), podem contribuir para o desenvolvimento infantil, tanto social como linguístico-cognitivo (MORAIS, 2013; CUNNINGHAM; STANOVICH, 1997; BUS et al., 1995; PARKES, 2000).

Em consonância com Hoover e Gough (1990) e outros pesquisadores que estudam as bases cognitivas da leitura (DEHAENE, 2012; MORAIS, 2013), partimos da concepção de que a compreensão leitora depende fortemente do conhecimento linguístico e de habilidades de decodificação rápida e acurada. Para que tais habilidades sejam desenvolvidas, as pesquisas indicam que a atuação de educadores em uma orientação prospectiva, antes da entrada da criança no ensino formal, pode ser decisiva para reduzir o número de crianças que não conseguem ler e escrever de forma qualificada e fluente nas séries iniciais, particularmente para as crianças provenientes de grupos socioeconomicamente menos favorecidos. A linguagem escrita possui características que lhe são peculiares em termos de densidade e diversidade lexical, construções sintáticas, processos de referenciação anafórica e catafórica, dentre outras. A familiaridade da criança com essa modalidade de linguagem pode contribuir para a compreensão em leitura nos anos de escolarização formal. Além disso, o desenvolvimento da consciência lin- 
guística em relação à forma como a escrita alfabética representa a linguagem, já nos primeiros anos de vida, pode auxiliar crianças aprender a ler e escrever com mais facilidade e prazer.

Nesse sentido, a questão de pesquisa que norteia o presente artigo é como auxiliar as crianças na infância a desenvolverem os requisitos necessários para a leitura compreensiva autônoma na adolescência e na vida adulta? A seção que segue apresenta uma revisão da literatura científica sobre a prática da leitura compartilhada de livros na primeira infância. Na sequência, nosso foco serão pesquisas que investigam o papel do direcionamento da atenção por meio de questionamentos conduzidos pelo adulto. Esta é a questão que move muitos estudos sobre leitura compartilhada, como o que apresentamos neste artigo.

\section{A leitura compartilhada de livros na primeira infância}

A expressão "leitura compartilhada" será tomada neste artigo para referirse ao momento em que um adulto (pais ou professores) e a criança (filhos ou alunos), independentemente de essa saber ou não ler, olham juntos para o livro, num episódio de atenção conjunta (TOMASELLO, 2003) em que a atenção é direcionada para os elementos que compõem o livro por meio da interação ativa suscitada pela leitura e pelo livro (ZUCKER et al., 2013; PENTIMONTI et al., 2012; GABRIEL; MORAIS, 2017). Episódios de atenção conjunta entre adulto e criança, em que o livro de história é o referente da atenção de ambos, representam uma rica oportunidade de aprendizagem e desenvolvimento linguístico, pois possibilitam o mapeamento entre palavras (sequências sonoras) e seus referentes representados no livro, para o o qual o adulto pode facilmente apontar e a criança pode identificar, associando palavras e objetos (KARRASS; BRAUNGART-RIEKER, 2005). Assim, a leitura à qual nos referimos vai além da rotina tradicional em que o adulto faz a leitura do livro e a criança escuta passivamente. Durante a leitura compartilhada, tanto a criança como o adulto são sujeitos ativos na elaboração de um diálogo, que pode se referir ao enredo, às personagens, à memória de experiências que emergem a partir da leitura, a palavras específicas, à disposição do texto e imagem na folha ou na tela, a aspectos da linguagem escrita ou conhecimentos que são novos para a criança (PIANTA; LA PARO, 2003).

De acordo com Anderson (1985), a leitura compartilhada de livros para as crianças pequenas é considerada uma das atividades mais importantes para o desenvolvimento do conhecimento necessário para leitura proficiente. Dado que essa atividade pode, naturalmente e incidentalmente, aumentar o interesse das crianças em ler livros, fornecer informações factuais sobre o mundo e torná-los conscientes das relações entre letras e sons (BUS et al., 1995). Ou seja, por meio dessa prática as crianças têm a oportunidade de aprender, além de usufruir de outros benefícios, de uma forma natural, antes do ensino formal. A prática da leitura compartilhada de livros na educação infantil representa uma poderosa ferramenta para o desenvolvimento de habilidades importantes para a aprendizagem inicial da leitura, justamente, porque ocorre em um contexto signifi- 
cativo, interessante e motivador para as crianças pequenas (JUSTICE; SOFKA, 2010; SÉNÉCHAL, 2015; GABRIEL; MORAIS, 2017; EVANS; SAINT-AUBIN, 2005; SÉNÉCHAL; LEFEVRE, 2002; MORAIS, 2013; DUFF et al., 2015). Diferentemente das interações baseadas na linguagem oral "a leitura compartilhada de livros de imagens, em que aparecem também palavras ou frases, aumenta a exposição ao vocabulário e a conceitos que só muito raramente são utilizados nas conversas mediadas pela linguagem oral” (MORAIS, 2013, p. 02).

A leitura compartilhada contribui para o aprendizado de novas palavras porque o contexto em que leitura ocorre concede pistas semânticas e sintáticas sobre os significados de novas palavras, e as ilustrações, por sua vez, também ajudam as crianças a associarem as novas palavras aos seus referentes (SÉNÉCHAL et al., 1995). Além do incremento no vocabulário, essa atividade também contribui para o desenvolvimento de habilidades mais elementares, como conhecimento do alfabeto (conhecimento dos nomes e sons de letras associadas), a consciência fonológica (capacidade de detectar, manipular ou analisar os aspectos sonoros da linguagem oral, incluindo a capacidade de distinguir ou segmentar palavras, sílabas ou fonemas, independentemente do significado), o conhecimento sobre a linguagem escrita (ordem da páginas, autor, título do livro, direcionalidade da escrita - da esquerda para a direita), significado que a linguagem escrita possui no meio em que vivemos (funções da linguagem escrita, contextos em que ela é usada), as quais são consideradas habilidades precursoras para a aprendizagem da leitura (STORCH; WHITEHURST, 2002; JUSTICE et al., 2009; NELP, 2008).

Entretanto, o desenvolvimento de tais habilidades depende da maneira como o adulto interage com a criança, ou seja, no modo como o adulto deliberadamente encoraja o envolvimento e participação da criança, enquanto busca significado e constrói conhecimento (JUSTICE; SOFKA, 2010). O elemento-chave para a garantir uma leitura compartilhada de qualidade, em que ambos interajam entre si, é a intencionalidade do leitor adulto, o qual cautelosamente conduz a leitura para, propositadamente, desafiar e ampliar as habilidades das crianças a fim de impulsioná-las no caminho de aprendizagem, especialmente, no desenvolvimento da linguagem e habilidades iniciais de alfabetização (PIANTA; LA PARO, 2003).

Uma meta-análise proposta por BUS et al. (1995), com o objetivo de investigar os efeitos da leitura compartilhada no desenvolvimento linguístico da criança, analisou os efeitos de 41 estudos (16 estudos sobre a leitura compartilhada e ganhos em linguagem; 16 estudos sobre a leitura compartilhada e alfabetização emergente; e, 9 estudos sobre a leitura compartilhada e habilidades em leitura). Os resultados desta meta-análise mostraram que os efeitos que a leitura compartilhada fornece ao desenvolvimento dessas habilidades variam de $(\mathrm{d}=0,67)$ para habilidades de linguagem, $(\mathrm{d}=0,58)$ para habilidades iniciais de alfabetização e $(d=0,55)$ para habilidades de leitura; ou seja, os efeitos dessa atividade são constatados e reconhecidos por diversos estudos.

Uma das premissas para o investimento em atividades de leitura interativa de livros fundamenta-se na teoria sociocultural defendida por Vygotsky (1978). Conforme essa visão, as crianças aprendem mais e melhor quando vivenciam 
atividades colaborativas, que envolvem um adulto, o qual pode apoiá-la na compreensão de um dado tópico e estimulá-la no avanço de sua aprendizagem, conceito conhecido como Zona de Desenvolvimento Proximal (ZPD). Segundo essa visão teórica, as crianças se beneficiam nas interações em que o adulto ajusta a atividade de aprendizagem para além do nível de conhecimento atual da criança, mas ao mesmo tempo não tão além que torne a aprendizagem inacessível (DANIS et al., 2000; VYGOTSKY, 1978). Nesse sentido, a leitura compartilhada eficaz é aquela em que o leitor adulto procura envolver ativamente a criança nas trocas verbais durante a atividade; ou seja, quanto mais a criança se sentir envolvida no desenrolar da história, mais chances ela tem de participar, questionar, opinar, fazer relações com o seu mundo e a sua vida.

\section{A formulação de perguntas como um tipo de conversa extratextual}

Em contexto de interação, a formulação de perguntas pelo adulto leitor tem sido considerada parte de um grupo de comportamentos-chave indicados para auxiliar no desenvolvimento das habilidades de linguagem e alfabetização de crianças pequenas (ZUCKER et al., 2017). Tal argumento se baseia no fato de que as perguntas formuladas durante a leitura compartilhada, distintamente dos comentários, encorajam as crianças a fazer mudanças nas interações conversacionais, ampliando a sua experiência com a linguagem (MASSEY; PENCE; JUSTICE, 2008). E ainda, por consequência, a formulação de alguns tipos específicos de perguntas favorece a articulação do pensamento, unindo as ideias advindas de diferentes partes do texto, favorecendo o processo de compreensão da história (MCKEOWN; BECK, 2006).

A formulação de perguntas tem recebido atenção nos últimos anos justamente porque representa aproximadamente um terço dos discursos dos educadores da primeira infância em sala de aula (de RIVERA et al., 2005; MASSEY et al., 2008), constituindo-se como um dos recursos mais comumente utilizados na pré-escola. De acordo com Girolametto et al. (2000), quando se observa os tipos de interação entre professores e alunos, que ocorrem comumente no ambiente educacional, é possível indicar que a leitura compartilhada de livros é uma das atividades em que os professores mais frequentemente formulam questões para as crianças quando comparadas a outros tipos de brincadeiras.

Um estudo experimental, proposto por Ewers e Brownson (1999), investigou o efeito de duas condições de leitura (ativa $v s$ passiva) para o desenvolvimento de vocabulário e memória fonológica. Na condição ativa, por exemplo, o professor deveria investir na formulação de questões. Participaram deste estudo 66 crianças pré-escolares, que tiveram seus níveis de vocabulário e memória fonológica testadas antes das sessões de leitura compartilhada, e posteriormente, foram divididas de forma aleatória nas duas condições de leitura. Nas sessões de leitura compartilhada ativa, as crianças participavam ativamente, respondendo a questões e nas sessões de leitura compartilhada passiva, as crianças ouviam uma reformulação contendo um sinônimo familiar. Os resultados indicaram que 
crianças com maior conhecimento de vocabulário adquiriram significativamente mais palavras que as crianças com níveis inferiores de vocabulário e, além disso, que os participantes ativos na leitura compartilhada de livros adquiriram significativamente mais palavras do que os participantes passivos. Corroborando o estudo acima, outros estudos mostram que a leitura compartilhada em que o leitor adulto investe em estratégias intencionais de questionamento demonstra elevado impacto no desenvolvimento do vocabulário das crianças (OPEL et al., 2009; WASIK; BOND, 2001) e nas habilidades de linguagem expressiva (HARGRAVE; SÉNÉCHAL, 2000; LONIGAN; WHITEHURST, 1998).

Nesse sentido, sessões de leitura compartilhada, em que o leitor adulto interage com a criança, criam espaços para que ela participe ativamente, além de contribuir para a ampliação de vocabulário, o que auxilia diretamente na compreensão do texto e reforça o significado de palavras conhecidas. Entretanto, nem a interação, nem a formulação de perguntas durante a leitura compartilhada são comportamentos padrões ou frequentes em todas as salas de aula da educação infantil. Existe uma variabilidade considerável nos estilos de leitura de livros que ocorrem naturalmente. McKeown e Beck (2006) verificaram que professores da pré-escola e primeiro ano liam para seus alunos, mas eles não envolviam as crianças em conversas extratextuais, ou seja, o padrão de comportamento mais frequente observado pelos pesquisadores foi professores lendo a história do início ao fim sem nenhuma contribuição das crianças (criança numa situação passiva). Os mesmos autores mencionam que, nas raras classes em que havia interação, a conversa extratextual circundava em torno da formulação de perguntas simples pelo professor, pedindo às crianças que recuperassem uma ideia do texto que acabara de ser proferida (por exemplo, O que o menino estava comendo? Sopa de letrinhas.). A formulação de perguntas em que a criança é instigada a responder com apenas breves respostas (respostas com sim/não, ou com uma palavra apenas) foi frequente em outras pesquisas (BECK; MCKEOWN, 2001; de RIVERA et al., 2005; GIROLAMETTO et al., 2000).

O tempo que o professor dedica e o tipo de questões que formula, durante a leitura compartilhada, têm um papel fundamental. Um estudo desenvolvido por Bowles et al. (2018) revelou que os professores conversam mais sobre temas relacionados à literacia (referência a letras e palavras e convenções sobre a escrita) antes do início da leitura (38\%), quando comparado às conversas durante (4\%) e depois (5\%) da sessão de leitura. Os professores centraram suas falas em conversas relacionadas ao sentido do texto durante (60\%) e após a leitura (63\%). Quanto aos questionamentos, esses ocorreram de forma equilibrada antes, durante e após a sessão de leitura.

As perguntas que instigam as crianças a se concentrarem nas ideias da história, em como se inter-relacionam, e que promovem mais oportunidades de a criança refletir, são mais eficazes do que aquelas em que a resposta pode ser rapidamente e facilmente recuperada (TEALE; MARTINEZ, 1996). Com o objetivo de analisar a relação entre as falas extratextuais dos professores com os ganhos de vocabulário das crianças ( 189 crianças, entre 3 e 6 anos de idade), Pentimonti 
et al. (2018) codificaram as falas extratextuais de 66 professores norte-americanos, por meio da ferramenta Systematic Assessment of Book Reading SABR 2.1, doravante (ZUCKER et al., 2017). Os códigos elencados para esse estudo foram divididos em dois tipos:

a. códigos relacionados ao uso de questões:

- Wh-questions - quem, o que/qual, quando, onde + formulário de sentença interrogativa

- Why-questions - por que + formulário de sentença interrogativa;

- How-questions - como + formulário de sentença interrogativa;

- Auxiliary-fronted questions - verbos auxiliares específicos da língua inglesa;

- Open questions - questões abertas que requerem múltiplas palavras $(2+$ word);

- Closed questions - questões fechadas que podem ser respondidas com apenas uma palavra;

- Yes/no questions - questões que podem ser respondidas com sim ou não.

b. códigos relacionados ao significado:

- Definir palavras e vocabulário,

- Efeitos causais e problemas - estimular o uso de inferências em uma cadeia causal entre a ação desenvolvida na história e a previsão de uma próxima informação.

Os resultados dessa pesquisa revelaram que a utilização de códigos relacionados ao significado e a alguns tipos de questões mais sofisticadas (quem, o que/ qual, por que) estavam associadas com ganhos no vocabulário das crianças. A formulação de questões em que a resposta poderia ser sim ou não (closed questions), consideradas pelos pesquisadores como menos sofisticadas, não foi associada a ganhos no vocabulário.

Ao mesmo tempo em que a formulação de perguntas se mostra um importante comportamento do adulto leitor, durante a prática da leitura compartilhada, nem todas as questões são semelhantes no que demandam cognitivamente da criança (MASSEY et al., 2008). As perguntas em que a criança pode responder sim ou não como, por exemplo, A chapeuzinho tinha medo do lobo mau? recrutam diferentes processamentos cognitivos quando comparadas com a formulação que perguntas básicas como, por exemplo, O que a chapeuzinho fez para despistar o lobo mau?. Nesse sentido, a frequência e o tipo de questão que os professores formulam, durante a leitura compartilhada, são fundamentais para incentivar a participação da criança e auxiliar no desenvolvimento da linguagem.

Crianças pequenas se beneficiam quando o adulto investe no uso de questões inferenciais, as quais requerem delas processos cognitivos mais elevados, como inferência, previsão, raciocínio ou explicação, pois são os tipos de 
perguntas que os leitores proficientes geram para melhorar sua compreensão (van KLEECK, 2003). A partir desses resultados, podemos suspeitar que as questões que demandam um processamento cognitivo mais elevado por parte da criança (por exemplo, "Por que o menino estava chorando?" "Como a mamãe se sentiu quando seus filhos lhe fizeram as pazes?", "Onde a menina estava quando o cachorro sumiu?", "Qual foi a reação da professora quando viu que a sala estava vazia?”) contribuem para o seu desenvolvimento linguísticocognitivo, justamente, porque a resposta não está dada, pois é necessário que a criança faça relações entre os dados da história.

Tendo em vista a importância da formulação de perguntas pelo professor, durante a leitura compartilhada, o presente estudo pretende analisar quais são os tipos de questões mais frequentes formuladas pelos professores brasileiros, durante a leitura compartilhada de livros na educação infantil. Até este momento, pelo que sabemos, este é o primeiro estudo que examinou a formulação de questões por professores pré-escolares brasileiros, durante a leitura compartilhada de livros infantis. A respeito disso, o estudo pode ser visto como exploratório em sua atenção para abordar dois objetivos: (1) determinar a frequência com que os professores fazem perguntas durante a leitura compartilhada de livros com os alunos; e (2) determinar os tipos de perguntas mais frequentes, em relação às perguntas básicas versus complexas.

\section{Investigando tipos de questões formuladas durante a leitura compartilhada}

\subsection{Participantes}

Participaram do estudo nove professoras, com idades entre 33 e 48 anos, com uma média de 38,4 anos de idade, sete delas atuando em escolas de educação infantil da rede pública e duas professoras em uma escola da rede privada. A experiência de ensino na educação infantil variou de 1 a 30 anos, sendo que apenas uma das professoras tinha entre 20 e 30 anos de experiência, seis entre 10 a 20 anos de experiência, uma entre 4 a 10 anos e uma com menos de 1 ano de experiência. Todas as professoras possuíam ensino superior completo ( $\mathrm{n}=$ 9), enquanto $77,7 \%$ possuíam especialização $(n=7)$ e uma professora havia concluído mestrado e estava com doutorado em andamento. Os dados estão resumidos na Tabela 1.

Tabela 1 - Dados dos professores participantes

\begin{tabular}{|l|l|l|}
\hline T & QT. & \% \\
\hline Participantes & 9 & \\
\hline Professores & 9 & \\
\hline Gênero & 9 & \\
\hline Feminino & 9 & \\
\hline
\end{tabular}




\begin{tabular}{|l|l|l|}
\hline Idade & 7 & $77,7 \%$ \\
\hline $30-40$ anos & 2 & $22,2 \%$ \\
\hline $40-50$ anos & 38,4 anos \\
\hline Média & 9 & $100 \%$ \\
\hline Titulação Acadêmica & 8 & $88,8 \%$ \\
\hline Graduação & 1 & $11,1 \%$ \\
\hline Especialização & 1 & $11,1 \%$ \\
\hline Mestrado & \multicolumn{2}{|l|}{} \\
\hline Doutorado & 1 & $11,1 \%$ \\
\hline Experiência profissional & 1 & $11,1 \%$ \\
\hline$>1$ ano & 6 & $66,6 \%$ \\
\hline $4-10$ anos & 1 & $11,1 \%$ \\
\hline $11-20$ anos &
\end{tabular}

Fonte: dados do estudo.

Com relação ao número de alunos nas salas de aula, 77\% $(\mathrm{n}=7)$ das professoras atendiam entre 10 a 20 alunos e $22 \%(n=2)$ atendiam mais de 30 crianças nas salas de aula. A faixa etária dos alunos variou entre 3 a 5 anos.

Os dados sobre leitura de livros nas salas de educação infantil evidenciaram que dois terços dos professores (67\%) costumam fazer leitura de livros infantis para as crianças de 2 a 3 vezes por semana. Sobre o tipo de contato com os livros, $77 \%$ dos professores $(\mathrm{n}=7)$ disseram que os alunos podem manusear livremente os livros, que estão disponíveis dentro da sala de aula. Por outro lado, apenas uma, das três escolas participantes, oferece biblioteca escolar com empréstimo de livros para os alunos.

\subsection{Procedimentos para a produção de dados}

Inicialmente, foram contatados os coordenadores pedagógicos de uma Secretaria Municipal de Educação e de uma escola privada, explicitando os objetivos da pesquisa e buscando a autorização para realizá-la no espaço escolar. Esses coordenadores indicaram quais seriam os professores, bem como as turmas que poderiam participar da coleta de dados. A partir disso, reunimo-nos com os professores indicados, explicamos os procedimentos e coletamos as assinaturas dos Termos de Consentimento Livre e Esclarecido, exigido pelo Comitê de Ética (Parecer N 2.957.086), e por fim, agendamos dia e horário das filmagens das duas sessões de leitura compartilhada. Para esse momento, os professores foram orientados a fazerem a leitura compartilhada de forma habitual e foram orientados a escolherem um livro para cada uma das sessões. Os pesquisadores instalaram a câmera para a filmagem e se retiraram da sala durante a sessão, solicitando ao professor que os chamassem quando terminasse a leitura do livro. Os dias e horários das gravações foram sugeridos pelos professores, sendo dias diferentes para cada uma das sessões. A coleta de dados foi realizada entre os meses de junho e 
setembro de 2018, nas três escolas participantes.

\subsection{Procedimentos para a análise de dados}

Os dados foram analisados por meio de uma versão adaptada do SABR 2.1 (ZUCKER et al., 2017), uma ferramenta gratuita, válida e confiável, projetada para codificar eficientemente as sessões de leitura compartilhada realizadas com crianças e professores da pré-escola até o primeiro ano. A ferramenta tem como objetivo capturar a frequência de comportamentos-chave que são conhecidos por promover as habilidades de linguagem e alfabetização de crianças pequenas. São codificadas todas as falas extratextuais antes, durante e depois da leitura compartilhada, ou seja, conversas entre o professor e os alunos, que vão além da leitura do próprio texto. A leitura que o professor faz do texto não é codificada, pois essa é a sua própria contribuição para a sessão de leitura compartilhada. Os enunciados considerados inaudíveis, ou seja, aqueles que não são compreensíveis após uma segunda tentativa de audição, são excluídos da codificação.

Nesse estudo, utilizamos uma versão adaptada para o português brasileiro da ferramenta porque, até esse momento, esse é o primeiro estudo brasileiro a utilizar o SABR 2.1 (ZUCKER et al., 2017) como ferramenta para codificar e analisar as sessões de leitura compartilhada.

Para a análise das falas extratextuais, utilizamos apenas um dos cinco códigos propostos no instrumento, presentes na versão adaptada da ferramenta (short-form), ${ }^{1}$ o qual categoriza e quantifica os códigos de expressão presentes na fala do professor no formato de perguntas. Além disso, incluímos nos dados apenas as falas extratextuais que ocorreram durante a leitura do livro; isto é, a coleta começa a partir do momento em que o professor chama a atenção das crianças para o livro e termina quando o professor faz a transição para uma nova atividade. A Tabela 2 apresenta as diretrizes de análise propostas pelo SABR 2.1 (ZUCKER et al., 2017) e exemplos de cada tipo de questão.

Tabela 2 - Diretrizes para análise das falas extratextuais de acordo com o Systematic Assessment of Book Reading-Transcript Coding Version 2.1. (SABR 2.1)

\section{Questões básicas \\ Questões básicas + forma interrogativa da sentença}

Palavras-chave: quem, o que, quando, onde, qual

- As perguntas começam com ou contêm uma palavra de pergunta e são colocadas como uma pergunta para obter uma resposta.

- Frases interrogativas que são usadas para fazer perguntas e são projetadas para provocar uma resposta.

- Podem ser codificadas perguntas que contenham uma

palavra-chave em uma posição diferente da posição inicial - "A mamãe ursa estava com quem no colo?"
- O que aconteceu?

- Quem é esse personagem?

- Quando ela se sentiu feliz?

- Qual foi a escolha dele?

- Onde o Pedro foi buscar o cachorro? 


\begin{tabular}{|l|l|}
\hline $\begin{array}{l}\text { Questões complexas } \\
\text { Por que + forma interrogativa da sentença } \\
\text { Como + forma interrogativa da sentença }\end{array}$ \\
\begin{tabular}{l|l|} 
- Frases interrogativas que são usadas para fazer uma pergunta \\
e devem incluir a palavra "por que".
\end{tabular} & $\begin{array}{l}\text { - Por que eles estão brigando? } \\
\text { - Por que você acha isso? } \\
\text { - Ela fez isso por que? }\end{array}$ \\
\hline $\begin{array}{l}\text { - Frases interrogativas que são usadas para fazer uma pergunta } \\
\text { e devem incluir a palavra "como". }\end{array}$ & $\begin{array}{l}\text { - Como isso se compara a ....? } \\
\text { - Como você sabe disso? } \\
\text { - Como o menino se sentiu? } \\
\text { - Como ela fez para limpar a boca? }\end{array}$ \\
\hline
\end{tabular}

Fonte: SABR 2.1 (ZUCKER et al., 2017) (traduzido e adaptado pela primeira autora).

Todas as perguntas formuladas pelos professores, durante as dezoito sessões de leitura compartilhada, foram transcritas e, posteriormente, codificadas nas categorias: questões básicas e questões complexas. Como informado anteriormente, neste artigo não serão analisadas as respostas das crianças.

\subsection{Resultados}

A formulação de questões pelos professores que participaram deste estudo representou $32 \%$ do total das falas extratextuais durante as sessóes de leitura compartilhada.

Durante as dezoito sessões de leitura compartilhada, os professores formularam um total de 329 questóes. As questões básicas, aquelas que utilizam as expressões "quem", "o quê", "quando", "onde", "qual" foram formuladas mais frequentemente $(n=285)$, representando $87 \%$ das questões formuladas. As questões complexas, que envolvem o uso de "por que" e "como", foram formuladas com menos frequência ( $\mathrm{n}=44$ ), constituindo $13 \%$ do total de questões. De modo geral, os professores fizeram uma média de 18,2 questões por sessão de leitura compartilhada. O Gráfico 1 mostra o percentual dos tipos de questões formuladas pelos professores nas dezoito sessões de leitura compartilhada.

Gráfico 1 - Tipos de questão por expressão

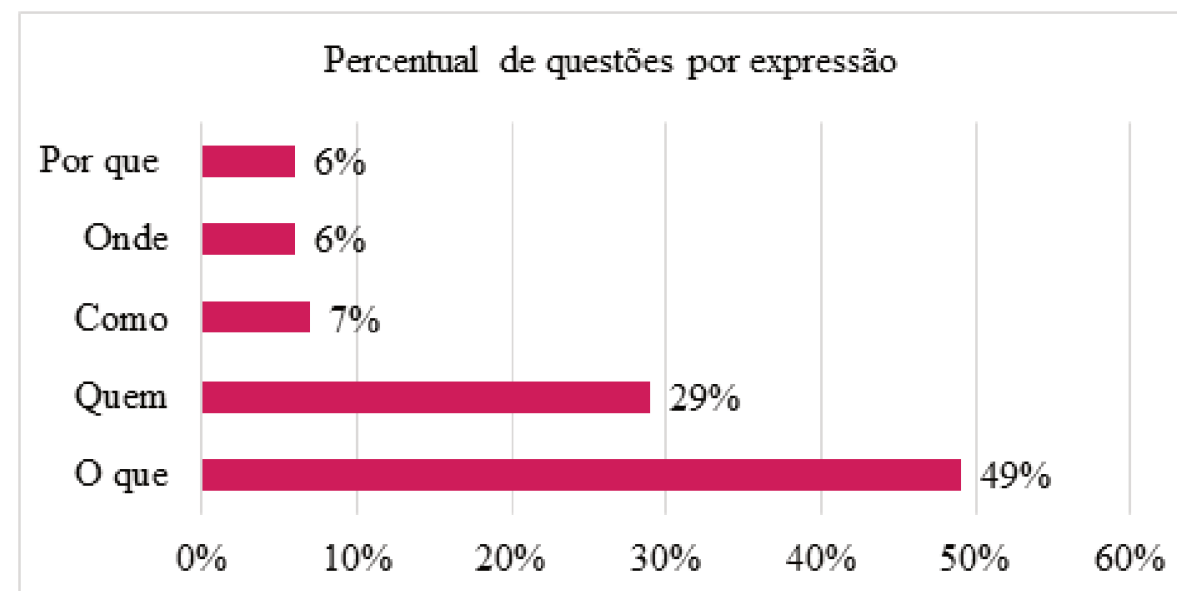

Fonte: dados do estudo. 
No elenco das questões básicas, duas delas foram elaboradas mais frequentemente: questões com uso de "o que" ( $\mathrm{n}=160)$ e com o uso de "quem" ( $\mathrm{n}=$ 95). Perguntas com a expressão "onde" foram proferidas 21 vezes. Por outro lado, perguntas com o uso das expressões "quando" $(n=6)$ e "qual" $(n=3)$ foram bem menos frequentes, representando apenas $3 \%$ do total de perguntas básicas.

Gráfico 2 - Visão geral das questões básicas

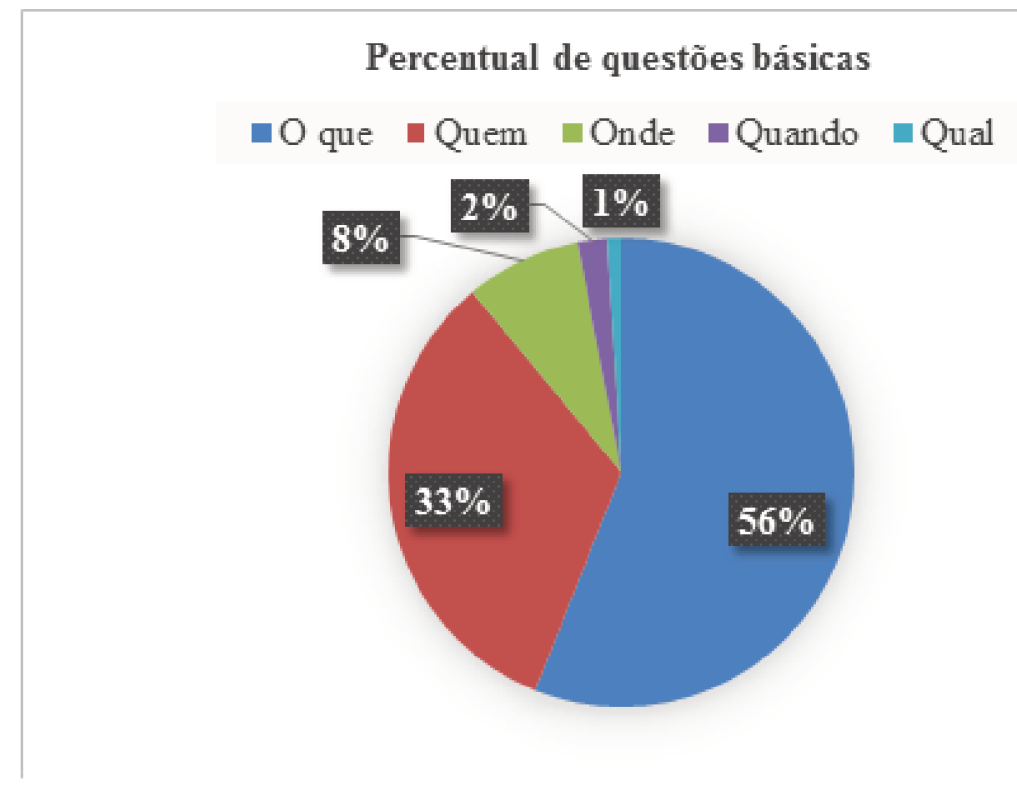

Fonte: dados do estudo.

Conforme podemos observar no Gráfico 2, as questões com o uso da expressão "o que" representaram mais da metade do total de questões básicas formuladas (56\%) nas sessões de leitura compartilhada conduzidas pelos professores. Esse percentual representa uma média de 8,8 questões por sessão.

Os dados sobre a formulação de questões com o uso da expressão "quem", formulada 33\% ( $\mathrm{n}=95)$ do total de questões básicas, evidenciam uma média de 5,2 questões por sessão de leitura compartilhada. As demais expressões, perguntas com o uso de "onde", foram formuladas uma vez, em média, em cada sessão. Perguntas geradas com as expressões "quando" e "qual" não foram formuladas nas dezoito sessões de leitura compartilhada, apenas em duas sessões delas.

A elaboração das questões complexas corresponde a um percentual de $13 \%$ do total de perguntas elaboradas, nas dezoito sessões. Das 44 questóes complexas formuladas, 25 delas foram proferidas com a expressão "como", representando uma frequência de $57 \%$ do total de questões. As perguntas com uso da expressão "por que" foram formuladas 19 vezes, um percentual de $43 \%$ do total de perguntas com essas duas expressões.

Além dos tipos de questões elaboradas pelos professores, contabilizamos o percentual de perguntas por professor, durante as dezoito sessões de leitura compartilhada. O Gráfico 3 evidencia o total de questões formuladas por cada um dos professores participantes. 
Gráfico 3 - Formulação geral de questões por professor

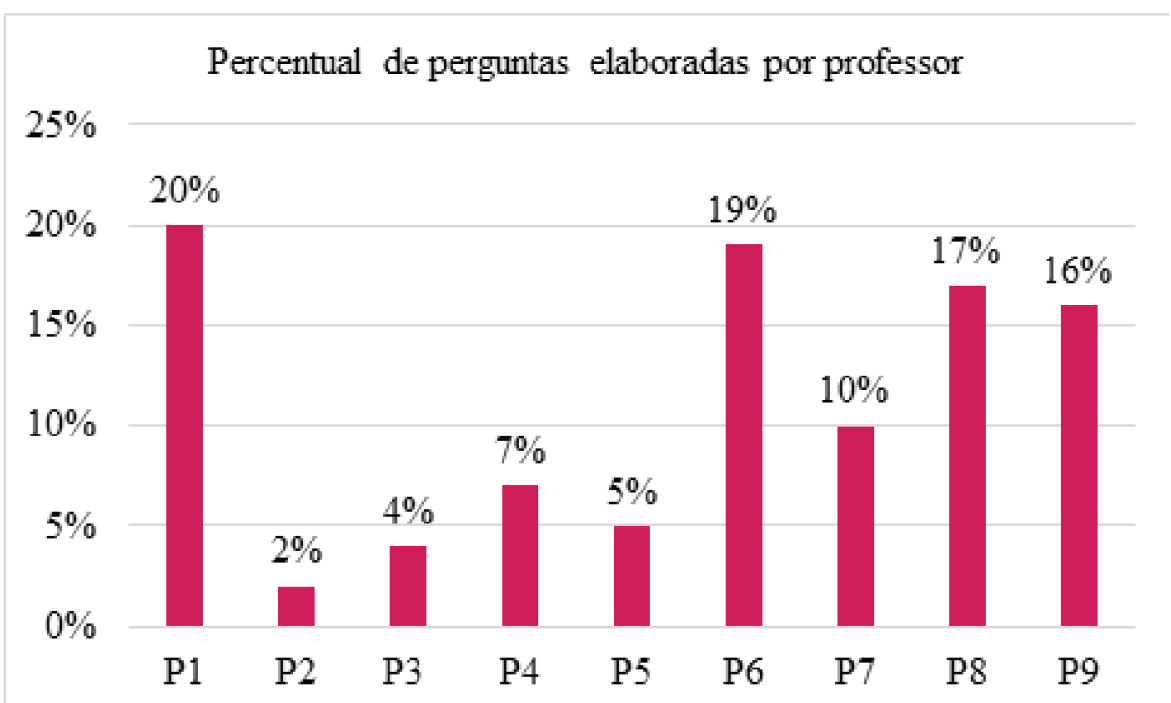

Fonte: dados do estudo. $(\mathrm{P}=$ professor $)$.

Como podemos observar, quatro professores (36\%) se sobressaíram quando contabilizamos o percentual de perguntas específicas por professor, ou seja, quatro professores formularam $72 \%$ do total de perguntas elaboradas $(n=329)$.

Também buscamos observar se houve diferença entre uma sessão e outra, com relação ao número de perguntas por professor. O Gráfico 4 evidencia o total de questões elaboradas por professor na primeira e na segunda sessão de leitura compartilhada.

Gráfico 4 - Dados sobre questões na sessão 1 e na sessão 2

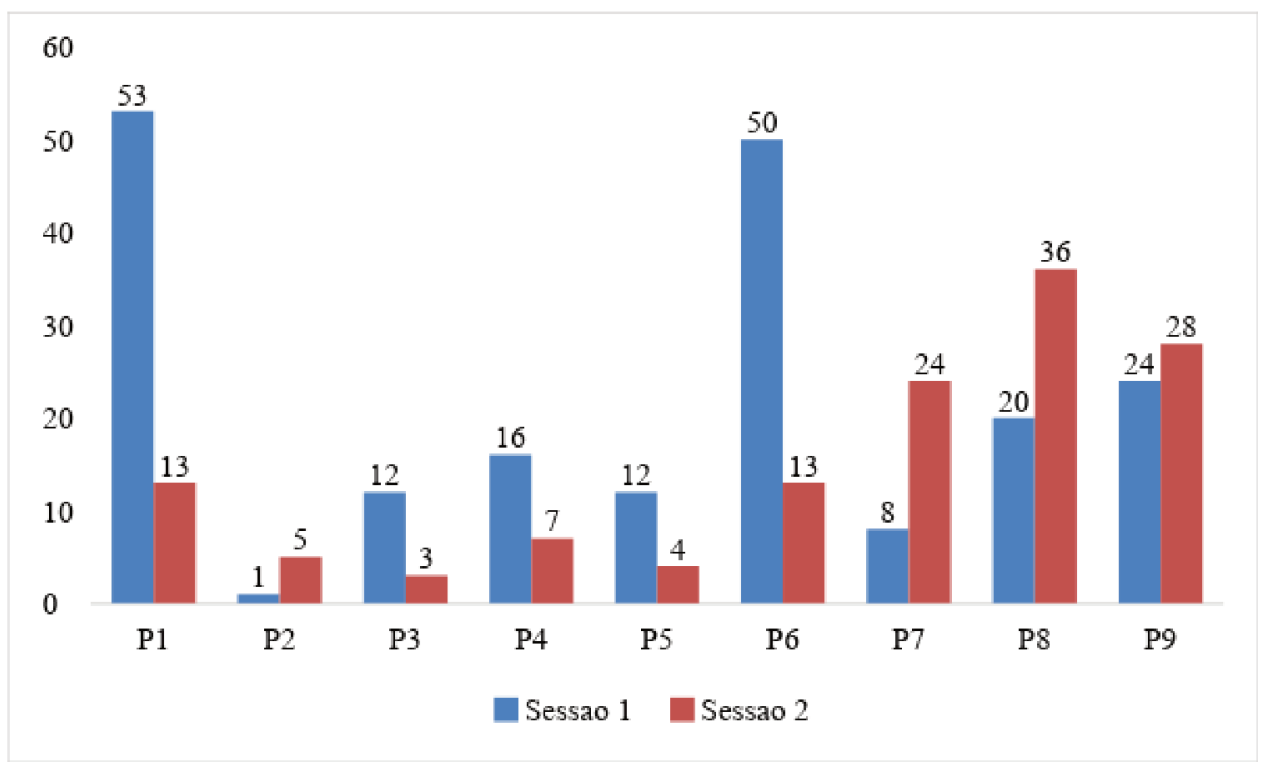

Fonte: dados do estudo. $(\mathrm{P}=$ professor $)$. 
Diante dos dados, é possível notar uma grande variabilidade no número de questões formuladas por cada professor (entre 1 e 53 questões), durante as dezoito sessões de leitura compartilhada. Da mesma forma, ao compararmos o número de questões entre uma sessão e outra, podemos observar que alguns professores formularam mais perguntas na sessão 1 e outros na sessão 2 . As diferenças entre os professores também ficam evidentes no tempo para a realização da leitura compartilhada (variabilidade de 3 a 32 minutos).

\subsection{Discussão}

Nosso foco de análise, neste estudo, concentrou-se no tipo de questões e a frequência em que os professores da educação infantil formularam perguntas às crianças, durante as sessões de leitura compartilhada. As respostas fornecidas pelas crianças, ou mesmo as perguntas feitas a partir da leitura do professor, também são de nosso interesse; entretanto, serão objeto de um trabalho posterior.

Os dados evidenciam que, do total de conversas extratextuais geradas pelos professores, 32\% foram direcionadas à elaboração de questões. Assim, os resultados apresentam uma consistência com outros estudos que analisaram a frequência do uso de questões durante a leitura compartilhada na pré-escola, os quais identificaram um total de 32.5\% (MASSEY et al., 2008) e 28.1\% (ZUCKER et al., 2010) das falas extratextuais direcionadas para a formulação de questões, durante a leitura compartilhada de livros.

Nesse sentido, podemos inferir que as crianças que vivenciaram a leitura compartilhada foram convidadas a interagir, a não permaneceram numa situação de escuta passiva, em que o professor lê e a criança apenas ouve. Tais evidências são importantes, pois a formulação de questões durante a leitura compartilhada, diferentemente de outros tipos de conversas, estimula as crianças a ampliar a sua experiência com a linguagem, tanto oral (variante mais coloquial) como escrita (variante padrão). Ao direcionar a atenção das crianças, a leitura compartilhada tem elevado impacto no desenvolvimento do vocabulário das crianças (MASSEY et al., 2008; OPEL et al., 2009; WASIK; BOND, 2001) e nas habilidades de linguagem expressiva (HARGRAVE; SÉNÉCHAL, 2000; LONIGAN; WHITEHURST, 1998).

Quando o leitor adulto aumenta a sua taxa de perguntas abertas (como, por exemplo, quem, quando, onde, porque, como, etc.), instiga a participação da criança nessa interação, por meio da linguagem e das relações cognitivas que ela estabelece para responder aos questionamentos (WHITEHURST et al., 1994). Nesse sentido, a formulação de perguntas é acompanhada de outros códigos comportamentais, que estimulam a imaginação e o desenvolvimento linguísticocognitivo das crianças.

Com relação ao tipo de perguntas, os nossos dados corroboram outros estudos, os quais relatam que a formulação de questões básicas representa grande parte das questões elaboradas, sendo consideradas como o tipo de questão mais frequente durante essa atividade, na educação infantil (BECK; MCKEOWN, 2001). Entretanto, esse tipo de questão, de acordo com os mesmos autores, não 
contribui para o desenvolvimento de habilidades linguísticas mais rudimentares como a compreensão de uma história, por exemplo. Por outro lado, Pentimonti et al. (2018) mostraram que os professores que formularam questões envolvendo expressões "quem", "o que" (questões simples) e "por que" (questões complexas), desde que não fossem respondidas com sim/não ou com uma palavra apenas, estavam associadas com ganhos no vocabulário das crianças.

As questões complexas ("por que" e "como"), as quais demandam das crianças processos cognitivos mais elevados, nos quais habilidades de inferência, previsão, raciocínio ou explicação são necessários para fornecer respostas, tiveram uma frequência bem menor, o que também corrobora outros estudos (BECK; MCKEOWN, 2001; de RIVERA et al., 2005; GIROLAMETTO et al., 2000). Refletirmos sobre esses dados é de suma importância porque os tipos de questões elaboradas pelo professor são decisivos para o tipo de contribuição que o professor vai proporcionar à criança.

As questões simples, como podemos observar, contribuem para o desenvolvimento e para a ampliação do léxico e, por outro lado, as questões complexas auxiliam as crianças a desenvolverem habilidades mais refinadas, ligadas à compreensão e interpretação textual (DASCAL, 2006). As crianças pequenas são beneficiadas quando o professor faz questões inferenciais (complexas), solicitando processos cognitivos de inferência, previsão, raciocínio, os quais representam os tipos de perguntas que os leitores proficientes geram para melhorar sua compreensão (van KLEECK, 2003). Ambos os tipos de questão são importantes, não só para a aprendizagem da leitura, mas para o desenvolvimento de uma postura crítica, reflexiva e analítica a ser estimulada e vivenciada ao longo da vida.

Embora a leitura de uma história para crianças não seja tarefa difícil para um adulto que sabe ler, a experiência da leitura compartilhada, que tem como objetivo contribuir para o desenvolvimento de habilidades linguísticas de crianças pequenas, preditoras da aprendizagem da leitura, pode ser complexa e exigente (BECK; MCKEOWN, 2001). O que fazer, por que ou como talvez não seja claro para muitos professores. Os resultados provindos da análise de percentual de questões nas sessões de leitura compartilhada, específicas por professor, reforçam a hipótese de que talvez alguns professores não tenham consciência da relevância de instigar as crianças a pensarem sobre o texto lido. Uma das possíveis explicações para essa variação pode estar no tipo de livro escolhido pelos professores. Todos eram do tipo narrativo, mas houve uma diferença considerável na quantidade de páginas (de 12 a 32 páginas). Além disso, o gênero ou mesmo outras características do próprio texto podem ter influenciado os tipos de perguntas, a quantidade de fala extratextual, bem como alterar o conteúdo, a diversidade de vocabulário e as expressões utilizadas nas falas, justamente porque o livro é o foco de atenção conjunta durante a atividade e fornece o tema em torno do qual as interações ocorrem.

Além das características do livro e da forma como o professor conduz o momento da leitura compartilhada, uma das possibilidades de explicação para as diferenças entre os participantes pode estar no contexto de sala de aula, que en- 
volve o estado de espírito das crianças (calmos $v s$ agitados), o horário em que a leitura foi proposta (início da aula, após intervalo ou antes de terminar a aula), o interesse das crianças na temática e, especialmente, o modo como o livro é apresentado para a criança, pois essas características podem interferir na qualidade, no tipo de interação e no tempo de duração. Apesar de o comportamento das crianças não ser o foco desse estudo, observamos nos vídeos produzidos nesta pesquisa manifestações de crianças pedindo ao professor para enxergar o livro, para ver as ilustrações e o contexto da história. É importante que os professores compartilhem com as crianças tanto a linguagem verbal quanto as imagens que constituem o texto. Como uma possível alternativa, o professor pode utilizar livros maiores ou mesmo projetar o livro, ou algumas páginas, acessar e-books, pois, dessa forma, poderá ofertar a todas as crianças as mesmas oportunidades de olharem o livro, perceberem as relações entre o texto e as ilustrações, visualizarem as letras e palavras, criando um ambiente propício e rico para a participação das crianças na atividade. Parkes (2000) explica que o ambiente e o contexto em que a leitura compartilhada ocorre é um dos elementos essenciais para garantir a qualidade da interação. A autora enfatiza que somente quando o grupo de alunos está confortavelmente sentado, hábil para enxergar o livro (e tudo o que ele apresenta) e ouvir claramente a leitura, é que o professor consegue envolvê-los na atividade compartilhada.

Por outro lado, uma das limitações do nosso estudo foi o baixo número de professores participantes $(n=9)$, comparado com os estudos de Pentimonti et al. (2018) e Pentimonti et al. (2017), os quais analisaram o uso de questões durante a leitura compartilhada na pré-escola, em que a média gira em torno de 40 professores. Outra restrição do nosso estudo é que analisamos apenas duas sessões de leitura compartilhada de cada professor, ao invés de analisarmos seu comportamento em diferentes momentos (por exemplo, comparação entre com e sem instrução sobre como conduzir a leitura compartilhada e sobre como investir em diferentes tipos de questões) e, além disso, utilizando diferentes tipos de livros (como, por exemplo, informativos, narrativos, expositivos, poético).

\section{Conclusões}

A questão proposta na introdução deste artigo, "como auxiliar as crianças na infância a desenvolverem os requisitos necessários para a leitura compreensiva autônoma na adolescência e na vida adulta?", no intuito de modificar os baixos resultados brasileiros nas avaliações de desempenho em leitura, encontra uma possível alternativa na leitura compartilhada. No entanto, para que essa alternativa possa alcançar melhores resultados, é necessário fazer avançar os estudos sobre como, quando, com que frequência, com que atitudes, com que materiais de apoio, podemos realizar a leitura compartilhada. Paralelamente, precisamos criar espaços para que pesquisadores e professores da Educação Infantil possam compartilhar seus conhecimentos e suas dúvidas sobre as vantagens e dificuldades na condução das pesquisas e da ação pedagógica. 
Uma orientação que ajude os professores a perceberem as diferenças entre atitudes características da leitura compartilhada e da leitura em que se pressupõe uma atitude passiva por parte do aluno é apenas o começo. O investimento em formação e orientação de professores é algo importante e sensato, visto que resultados de estudos que buscaram direcioná-los a qualificarem a atividade da leitura compartilhada têm demonstrado benefícios. Wasik et al. (2001) propuseram um treinamento para professores de pré-escola a partir da implementação de estratégias interativas de leitura de livros e formulação de questões abertas, ou seja, aquelas que demandam mais esforço cognitivo das crianças, como uma das formas mais eficazes de promover a participação efetiva nas sessões de leitura compartilhada e, até mesmo, em outras atividades pedagógicas realizadas em salas de aula. Os resultados dessa preparação tiveram efeito positivo sobre o desenvolvimento das habilidades linguística das crianças.

A orientação do leitor adulto, tanto professores quanto pais ou familiares, sobre como otimizar a leitura compartilhada, para que possa, de fato, contribuir para o desenvolvimento linguístico das crianças, foi objeto de estudo de Whitehurst et al. (1988). Nesse projeto, um grupo de pais foi orientado a diminuir a frequência de leitura em que a criança fique em uma situação passiva, aumentar a taxa de perguntas abertas e diminuir as perguntas que poderiam ser respondidas apontando para o livro e com apenas uma palavra. Os pesquisadores descobriram que o uso desse tipo de perguntas resultou em ganhos significativos no conhecimento do vocabulário das crianças em um período de 4 semanas. Em contraste, as crianças cujos pais não formularam perguntas não demonstraram tais ganhos. Com base nesses resultados, podemos observar que orientar o adulto leitor para a condução da atividade da leitura compartilhada pode contribuir rapidamente e significamente para o incremento nos benefícios linguísticos que pode gerar para as crianças pequenas.

Por fim, a leitura compartilhada, iniciada nos primeiros anos de vida, pode auxiliar no desenvolvimento de uma postura analítica, reflexiva e crítica por parte das crianças em relação à leitura e, quiçá, à vida. A compreensão em leitura pressupõe um leitor intelectualmente ativo que coopera na construção dos sentidos do texto, preenchendo lacunas e prospectando desdobramentos.

Nota

1. A versão original do Systematic Assessment of Book Reading (SABR) pode ser acessado no link: https://cliengage.org/public/systematic-assessment-of-book-reading-sabr-2-0/.

\section{Referências}

ANA (2016). Avaliação Nacional da Alfabetização. Disponível em: http://portal.inep. gov.br/educacao-basica/saeb/sobre-a-ana. Acesso em: Jul. de 2018.

ANDERSON, R. Becoming a nation of readers: the report of the commission on reading. The National Institute of Education, 1985.

BECK, I. L.; MCKEOWN, M. G. Text Talk: capturing the benefits of read-aloud experiences for young children. The Reading Teacher, 55(1), 10-20, 2001. 
BUS, A. G., et al. Joint book-reading makes for success in learning to read: a metaanalysis on intergenerational transmission of literacy. Review of Educational Research, 65, 1-21, 1995.

BOWLES, R. P., et al. Teachers' use of extra-textual talk before, during, and after sharedreading sessions. Poster presented at the Twenty Fifth Conference of the Society for the Scientific Study of Reading (2018). Disponível em:https://cliengage.org/ public/wp-content/uploads/sites/10/2018/09/SSSR-2018.png. Acesso em: Jan. de 2019.

CUNNINGHAM, A. E.; STANOVICH, K. E. Early reading acquisition and its relation to reading experience and ability 10 years later. Developmental Psychology, vol 33(6), nov., 934-945, 1997.

DANIS, A. et al. Shared picture-book reading: A sequential analysis of adult-child verbal interactions. British Journal of Developmental Psychology, 18, 369-388, 2000.

DASCAL, M. Interpretação e compreensão. São Leopoldo: Editora Unisinos, 2006.

DUFF, F. J.; REEN, G.; PUNKLETT, K.; NATION, K. Do infant vocabulary skills predict school-age language and literacy outcomes? Journal of Child Psychology and Psychiatry 56:8, 848-856, 2015.

de RIVERA, C. et al. Children's responses to educators' questions in day care group play. American Journal of Speech-Language Pathology, 14, 14-26, 2005.

DEHAENE, S. Os neurônios da leitura: como a ciência explica a nossa capacidade de ler. Porto Alegre: Penso, 2012.

EWERS, C. A.; BROWNSON, S. M. Kindergarteners' vocabulary acquisition as a function of active vs. passive storybook reading, prior vocabulary, and working memory. Reading Psychology, 20, 11-20, 1999.

EVANS, M. A.; SAINT-AUBIN, J. What children are looking at during shared storybook reading. American Psychological Society. Volume 16 - Number 11, Pages 913-920, 2005.

GABRIEL, R.; MORAIS, J. O que precisamos saber sobre leitura? Contribuições interdisciplinares. Santa Maria: Editora UFSM, 2017.

GIROLAMETTO, L. et al. Directiveness in teachers' language input to toddlers and preschoolers in daycare. Journal of Speech, Language, and Hearing Research, Vol. 43, 1101-1114, 2000.

INEP. Instituto Nacional de Estudos e Pesquisas Educacionais Anísio Teixeira. Brasil no PISA 2015: análises e reflexões sobre o desempenho dos estudantes brasileiros/ OCDE-Organização para a Cooperação e Desenvolvimento Econômico. - São Paulo: Fundação Santillana, 2016.

HARGRAVE, A. C.; SÉNÉCHAL, M. A book reading intervention with preschool children who have limited vocabularies: the benefits of regular reading and dialogic reading. Early Childhood Research Quarterly, 15, 75-90, 2000.

HOOVER, W. A.; GOUGH, P. B. The simple view of reading. Reading and Writing: an interdisciplinary Journal 2: 127-160,1990.

JUSTICE, L. M.; KADERAVEK, J, N; FAN, X.; SOFKA, A.; HUNT, A. Accelerating preschoolers' early literacy development through classroom-based teacher-child storybook reading and explicit print referencing. Language, Speech, and Hearing Services In Schools, Vol. 40, 67-85, January 2009.

JUSTICE, L. M.; SOFKA, A. E. Engaging children with print: building early literacy skills through quality read-aloud. Copyright by The Guilford Press, 2010. 
KARRASS, J.; BRAUNGART-RIEKER, J. M. Effects of shared parent-infant book reading on early language acquisition. Applied Developmental Psychology 26, 133$148,2005$.

LONIGAN, C. J., \& WHITEHURST, G. J. Relative efficacy of parent and teacher involvement in a shared-reading intervention for preschool children from lowincome backgrounds. Early Childhood Research Quarterly, 13, 263-290, 1998.

MASSEY, S. L., et al. Educators' use of cognitively challenging questions in economically disadvantaged preschool classroom contexts. Early Education \& Development, 19, 340-360, 2008.

McKEOWN, M. G.; BECK, I.L. Encouraging young children's language interaction with stories. In: DICKINSON, D. K.; NEUMAN, S. B. Handbook of early literacy research. Vol 2. The Guilford Press, p. 281-294, 2006.

MORAIS, J. Criar leitores: para professores e educadores. Barueri, SP: Minha Editora, 2013.

NELP. NATIONAL EARLY LITERACY PANEL. Developing Early Literacy: report of the National Early Literacy Panel. Jessup: National Institute for Literacy, 2008.

OPEL A. et al. The effect of preschool dialogic reading on vocabulary among rural Bangladeshi children. International Journal of Educational Research, 48, 12-20, 2009.

PARKES, B. Read it again: revisiting shared reading. Stenhouse Publishers, Portland, Maine, 2000.

PENTIMONTI, J. M. et al. A standardized tool for assessing the quality of classroombased shared reading: Systematic Assessment of Book Reading (SABR). Early Childhood Research Quarterly 27, 512- 528, 2012.

PENTIMONTI, J. M., et al. The impact of teachers' extra-textual talk during shared reading on children's language/literacy skills. Poster presented at Society for the Scientific Study of Reading (2018). Disponível em: https://cliengage.org/public/ wp-content/uploads/sites/10/2018/09/SSSR-2018.2.png. Acesso em: Jan. de 2019.

PIANTA, R. C.; LA PARO, K. Improving early school success. Educational Leadership, 60(7), 24-29, 2003.

SÉNÉCHAL, M. Young children's home literacy experiences. In: TREIMAN, R. The Oxford Handbook of Reading. Oxford: Oxford University Press, 2015.

SÉNÉCHAL, M.; LEFEVRE, J. Parental involvement in the development of children's reading skill: A five-year longitudinal study. Child Development, 73, 445-460, 2002.

STORCH, S. A.; WHITEHURST, G. J. Oral language and code-related precursors to reading: evidence from a longitudinal structural model. Developmental Psychology, vol. 38, n. 6, p. 934 - 947, 2002.

TEALE, W. H.; MARTINEZ, M. G. Reading aloud to young children: teachers reading styles and kindergartens text comprehension. In: PONTECORVO, C. et al. (Ed.) Children's early text construction. Rome, Italy, 1996, p. 554-557.

TOMASELlO, M. Origens culturais da aquisição do conhecimento humano. São Paulo: Martins Fontes, 2003.

van KLEECK, A. (2003). Research on book sharing: another critical look. In: van KLEECK, A.; STAHL, A.; BAUER, E. B (Eds.). On reading books to children: parents and teachers. Mahwah, NJ, US: Lawrence Erlbaum Associates Publishers, p. 271-320, 2003. 
VYGOTSKY L. S. Mind in Society: the development of higher psychological processes. Cambridge, MA: Harvard University Press, 1978.

WASIK, B. A.; BOND, M. A. Beyond the pages of a book: Interactive book reading and language development in preschool classrooms. Journal of Educational Psychology, 93, 243, 2001.

WHITEHURST, G. J. Accelerating language development through picture book reading.

ZUCKER, T. A, et al. Preschool teachers' literal and inferential questions and children's responses during whole-class shared reading. Early Childhood Research Quarterly 25, 65-83, 2010.

ZUCKER, T. A., et al. The role of frequent, interactive prekindergarten shared reading in the longitudinal development of language and literacy skills. Developmental Psychology,49(8), 1425-1439, 2013.

ZUCKER, T. A. et al. Systematic Assessment of Book Reading-Transcript Coding Version 2.1. Unpublished instrument, University of Texas Health Science Center at Houston, Houston, TX, 2017. Developmental Psychology, 24, 552- 559, 1988.

WHITEHURST, G. J. et al. A picture book reading intervention in day care and home for children from low - income families. Developmental Psychology, 30, 679-689, 1994.

Recebido em: 04/03/2019

Aceito em: 04/07/2019 